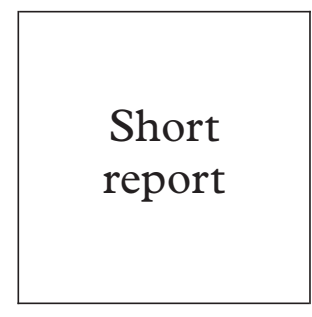

Division of Public Health and Environment, Municipal Health Service Amsterdam I G Stolte

N H T M Dukers

J B F de Wit

R A Coutinho

Department of Socia and Organisational Psychology, University of Utrecht

J B F de Wit

Sexually Transmitted Infections Clinic, Municipal Health Service Amsterdam J S A Fennema

Department of Human Retrovirology, Academic Medical Centre, University of Amsterdam

R A Coutinho

Correspondence to: I G Stolte, Municipal Health Service Amsterdam, Division of Public Health and Environment, Nieuwe Achtergracht 100, PO Box 22001000 CE Amsterdam, Netherlands

istolte@gggd.amsterdam.n

Accepted for publication 22 March 2001

\title{
Increase in sexually transmitted infections among homosexual men in Amsterdam in relation to HAART
}

\author{
Ineke G Stolte, Nicole H T M Dukers, John B F de Wit, Johan S A Fennema, \\ Roel A Coutinho
}

Objectives: We investigated if a rise in rectal gonorrhoea and early syphilis among men who have sex with men (MSM) in Amsterdam coincided with the introduction of highly active antiretroviral therapies (HAART) in July 1996 and determined risk factors for these sexually transmitted infections (STI).

Methods: Subjects were patients of the STI clinic of the municipal health service in Amsterdam. Surveillance data (1994-9) represented consultations $(n=11240)$ of MSM ( $n=6103)$. For analyses we used logistic regression.

Results: Comparing the periods before and after the introduction of HAART, the infection rate for rectal gonorrhoea increased from $4 \%$ to $5.4 \%(\mathrm{p}=.001)$ and for syphilis, from $0.5 \%$ to $0.8 \%$ $(p=0.050)$. Independent risk factors for rectal gonorrhoea (younger age, western nationality, and concurrent infection with another STI) and for early syphilis (non-western nationality and concurrent infection with rectal gonorrhoea) did not change after HAART became available. For rectal gonorrhoea, however, the infection rate increased only among men who had exclusively homosexual contacts ( $\mathrm{OR} 1.38, \mathrm{p}<0.01$ ), compared with bisexual men. For early syphilis, the infection rate increased only among men of western nationality $(\mathrm{OR} 3.38, \mathrm{p}<0.01)$ compared to men of non-western nationality.

Conclusions: Infection rates of rectal gonorrhoea and early syphilis increased, indicating a change in sexual behaviour, possibly as a result of the introduction of HAART. For now, it is important to find out how sexual behaviour is changing and to keep monitoring trends in STIs (including HIV) among MSM in Amsterdam.

(Sex Transm Inf 2001;77:184-186)

Keywords: rectal gonorrhoea; syphilis; HAART; high risk sexual behaviour; MSM

\section{Introduction}

Recently, reports from several cities in industrialised countries described a strong increase in gonorrhoea and syphilis among men who have sex with men (MSM). ${ }^{1-6}$ The present increase in gonorrhoea and early syphilis may be related to the introduction of highly active antiretroviral therapy (HAART) in July 1996, possibly because of an increase in high risk sexual behaviour due to treatment optimism..$^{7-9}$ In the present study we investigated whether the recently observed rise in rectal gonorrhoea and early syphilis at the STI clinic in Amsterdam coincides with the introduction of HAART, and which study groups are at highest risk in the periods before and after the introduction of HAART.

\section{Materials and methods}

The STI clinic in Amsterdam offers sexual health services free of charge, including the diagnosis and treatment of STIs. At every new consultation, information about sociodemographic characteristics is routinely collected and entered into a database under a patient identification code, and patients are routinely screened for (rectal) gonorrhoea and syphilis. An individual can have multiple new consultations in one year and/or more than one diagnosis per consultation. A positive culture was used as the diagnostic criterion for gonorrhoea (GC-Lect agar, BBL, Becton Dickinson, Cockeysville, USA). A diagnosis of early syphilis was based on clinical symptoms and a reactive serology. Treponema pallidum haemagglutination assay (TPHA, Fujirebio, Tokyo, Japan) was used for syphilis screening; when the assay was positive, the Venereal Disease Research Laboratory test (VDRL, Wellcome, Dartford, UK) and the FTA absorption test (Trepo-spot IF, Biomerieux, Marcy l'Etoile, France) were performed. Patients previously treated for syphilis were diagnosed with a new syphilis infection only when there was a threefold or more increase in VDRL titre

Table 1 Change in absolute number of cases and infection rates (\%) of the different STIs over the years (1994-9) among 11240 consultations made by men who have sex with men, Amsterdam STI clinic, 1994-9, Netherlands

\begin{tabular}{|c|c|c|c|c|c|c|c|}
\hline$S T I$ & $\begin{array}{l}1994(n=1410) \\
\text { No }(\%)\end{array}$ & $\begin{array}{l}1995(n=1545) \\
\text { No }(\%)\end{array}$ & $\begin{array}{l}1996(n=1837) \\
\text { No }(\%)\end{array}$ & $\begin{array}{l}1997(n=1886) \\
\text { No }(\%)\end{array}$ & $\begin{array}{l}1998(n=2100) \\
\text { No }(\%)\end{array}$ & $\begin{array}{l}1999(n=2462) \\
\text { No }(\%)\end{array}$ & $\begin{array}{l}\text { Change over the } \\
\text { years? (linear } \\
\text { trend) }\end{array}$ \\
\hline Rectal gonorrhoea & $56(4.0)$ & $61(3.9)$ & $87(4.7)$ & $96(5.1)$ & $83(4.0)$ & $167(6.8)$ & $\mathrm{p}<0.001$ \\
\hline Early syphilis & $6(0.4)$ & $5(0.3)$ & $15(0.8)$ & $8(0.4)$ & $9(0.4)$ & $35(1.4)$ & $\mathrm{p}=0.001$ \\
\hline
\end{tabular}




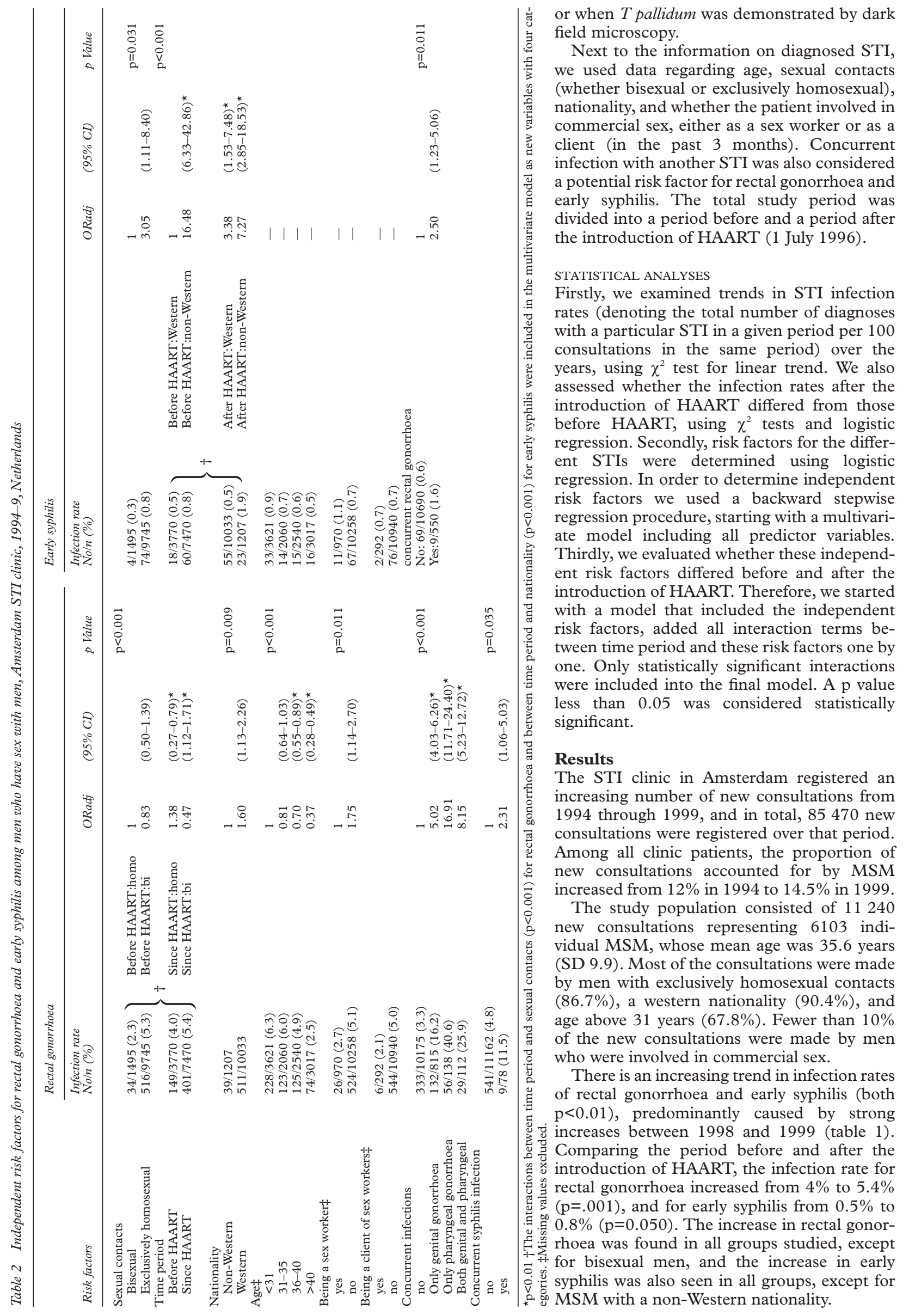


In both time periods independent risk factors for rectal gonorrhoea were younger age, having a Western nationality, and concurrent infection with another STI (table 2). Having exclusively homosexual contacts was an independent risk factor only in the period after HAART (OR: 2.97, 95\% CI: 1.78-4.97). Strikingly, the infection rate of rectal gonorrhoea among men with exclusively homosexual contacts increased after the introduction of HAART $(p=0.003)$, but decreased among bisexual men. This latter effect, however, was not statistically significant.

In both time periods, independent risk factors for early syphilis were having exclusively homosexual contacts, and having a concurrent infection with rectal gonorrhoea (table 2). Although having a non-Western nationality was also an independent risk factor in both time periods, the risk estimate (OR) considerably decreased in the period after the introduction of HAART. Moreover, since the introduction of HAART, the infection rate of early syphilis among men of non-Western nationality has decreased (marginally statistically significant), whereas the infection rate of syphilis among men of Western nationality has increased $(p=0.003)$. The group of men with a nonWestern nationality, as defined for this study, who had a diagnosis of early syphilis consisted predominantly of men with a Latin American nationality $(69.5 \%)$ or an eastern European nationality $(12.9 \%)$.

\section{Discussion}

Our study demonstrates that in addition to an increasing number of new consultations and a generally increasing pool of MSM attending the STI clinic, there is a rise in infection rates of rectal gonorrhoea and early syphilis in this group, as was found in studies in other Western countries. $^{1245}$ This increase coincided with the introduction of HAART, and continued in the year 2000 (unpublished data).

Rectal gonorrhoea and early syphilis are often used as markers for unprotected anal intercourse (UAI) ${ }^{10}$ and their rise in Amsterdam may indicate an increase in UAI. This would be in agreement with recent findings from a cohort of HIV negative young MSM in Amsterdam. ${ }^{11}$ Moreover, susceptibility to HIV infection is believed to be facilitated by the presence of these STIs. ${ }^{12}$ As a consequence, the increase in STI might suggest a risk for increased transmission of HIV in the near future.

The reported increase in rectal gonorrhoea is present in all groups studied, except among men with bisexual contacts, so having exclusively homosexual contacts is only an independent risk factor after the introduction of HAART. The increase in early syphilis was also seen in all groups under study, except among MSM with a non-Western nationality. However, MSM with a non-Western nationality still have the highest rates with syphilis, as have
MSM with exclusively homosexual contacts or with a concurrent infection with rectal gonorrhoea.

It seems plausible that before HAART was introduced, cases of early syphilis were few and resulted from new introductions by men of non-Western nationality, producing some secondary cases but not sufficient to sustain further spread. This situation seems to have changed and we are now witnessing a renewed spread of syphilis among MSM in Amsterdam.

In conclusion, infection rates of rectal gonorrhoea and early syphilis are increasing, indicating a change in sexual behaviour possibly as a result of the introduction of HAART. To date indirect evidence supporting this hypothesis is accumulating. ${ }^{7-11}$ However, there is a need for direct empirical testing of this reasoning. For now, it is important to keep monitoring trends in STIs (including HIV), especially among people at higher risk for these STIs such as, younger MSM, men with exclusively homosexual contacts, and MSM with a western nationality.

The authors thank the personnel of the STI clinic, headed by Irina Cairo, for their contribution in data collection, and the staff of the regional laboratory of the municipal health service, headed by Joke Spaargaren, for laboratory support, Ronald Geskus for critically reading the manuscript, and Lucy Phillips for editing the final manuscript.

Contributors:IS analysed and interpreted the data, and wrote the paper; ND gave substantial contributions to the analyses and interpretation of the data, and edited the paper; JF planned the study, contributed to the acquisition of data, and edited the paper; JdW contributed to the interpretation of data, supervised paper; JdW contributed to the interpretation of data, supervised study, contributed to the interpretation of data, and edited the paper.

1 Page-Shafer KA, McFarland W, Kohn R, et al. Increases in unsafe sex and rectal gonorrhoea among men who have sex with men-San Francisco, California, 1994-1997. MMWR 1999;48 (pt 3):45-8.

2 Handsfield HH, Whittington WLH, Desmon S, et al. Resurgent bacterial sexually transmitted disease among men who have sex with men-King County, Washington, 19971999. MMWR 1999;48 (pt 35):773-5.

3 Martin IMC, Ison CA. Rise in gonorrhoea in London, UK. London Gonococcal Working Group. Lancet 2000;355: 623.

4 Fenton KA, Rogers PA, Simms I, et al. Increasing gonorrhoea reports-not only in London. (Correspondence) Lancet 2000;355:1907.

5 Donovan B, Bodsworth NJ, Rohrsheim R, et al. Increasing gonorrhoea report-not only in London. (Correspondence) Lancet 2000;355:1908

6 Fennema JSA, Cairo I, Coutinho RA. Substantial increase in gonorrhoea and syphilis among attenders of the Amstedam sexually transmitted diseases clinic [Sterke toename van gonorrhoe en syfilis onder bezoekers van de Amsterdamse SOA polikliniek]. Ned Tijdschr Geneesk 2000;144 (pt13):602-3.

7 Ven van de P, Kippax S, Knox S, et al. HIV treatments optimism and sexual behaviour among gay men in Sydney and Melbourne. AIDS 1999;13:2289-94.

8 Vanable PA, Ostrow DG, McKirnan DJ, et al. Impact of combination therapies on hiv risk perceptions and sexual risk among HIV-positive and HIV-negative gay and risk among HIV-positive and HIV-negative gay

9 Elford J, Bolding G, Maguire M, et al. Combination therapies for HIV and sexual risk behavior among gay men. therapies for HIV and sexual risk behavior among

f Acquir Immune Defic Syndr 2000;23:266-71.
0 Renton AM, Whitaker L. Using STD occurence to monitor Renton AM, Whitaker L. Using STD occurence to mon
AIDS prevention. Soc Sci Med 1994;38 (pt 8):1153-65.

1 Dukers NHTM, Goudsmit J, de Wit JBF, et al. Sexual behaviour relates to the virological and immunological mprovements during highly active antiretroviral therapy in HIV-1 infection. AIDS 2001;15:369-78.

12 Page-Shafer K, Veugelers PJ, Moss AR, et al. Sexual risk behavior and risk factors for HIV-1 seroconversion in homosexual men participating in the tricontinental seroconverter study, 1982-1994. Am ₹ Epidemiol 1997;146 (pt 7):531-42. 